\title{
Ultrasonographic Alterations of Pancreas in Diabetic Patients
}

\author{
Siva Prasad Chavva ${ }^{1}$, Santosh U Karpur ${ }^{2}$ \\ ${ }^{1}$ Associate Professor, ${ }^{2}$ Assistant Professor, Department of Radiology, Malla Reddy Institute of Medical Sciences, Hyderabad, \\ Telangana, India
}

Corresponding author: Dr. Siva Prasad Chavva, Associate Professor, Department of Radiology, Malla Reddy Institute of Medical Sciences Sy No. 138, Suraram Main Road, GHMC Quthbullapur Jeedimetla, Hyderabad - 500 055., Telangana, India

DOI: http://dx.doi.org/10.21276/ijcmsr.2018.3.4.36

How to cite this article: Siva Prasad Chavva, Santosh U Karpur Ultrasonographic alterations of pancreas in diabetic patients. International Journal of Contemporary Medicine Surgery and Radiology. 2018;3(4):D160-D162.

\section{A B S T R A C T}

Introduction: Pancreas is insulin-producing gland and its subjected to injury and alteration in the diabetes-producing process. Ultrasonography $(\mathrm{U} / \mathrm{S})$ of pancreas can evaluate the gland in $95 \%$ of cases and its correctness in diagnosis of pancreatic disease equals with that of CT-scan. This Study was preformed to assess the pancreatic size of diabetic patients using ultrasonography and to ascertain whether there is a relationship between the size of the pancreas and the duration of diabetes.

Material and methods: Two groups (type 1 and type 2 DM) of 30 diabetic patients each were compared with healthy controls. Ultrasound examinations to measure pancreas head and diameter was preferred. The study included all patients above 20 years old, who had DM (type -1 and 2). Exclusion criteria - Patients of pediatric age group and had any pancreatic abnormalities (cirrhosis, thalassemia, pancreatitis, pancreatic tumors or cystic fibrosis). One-way ANOVA test and Student's T-test were performed to compare the size of head and body of pancreas and pancreas echogenicity in various groups.

Results: Mean pancreatic head and body size were 17.5 $\pm 2.5 \mathrm{MM}$ and 7.4 $\pm 1.6 \mathrm{MM}$, individually, in insulin-dependent diabetic patients, while these measurements were $21.1 \pm 3.5 \mathrm{MM}$ and $9.0 \pm 2.1 \mathrm{~mm}$, respectively, in noninsulin dependent diabetic patients, and $26.2 \pm 4 \mathrm{~mm}$ and $13.9 \pm 2.6 \mathrm{MM}$, correspondingly, in the control group. Diameter of pancreas was statistically significant in diabetic patients and correlated with duration of disease.

Conclusions: there was a reduction in the size of pancreas in type I diabetes when compared with that of type II diabetes and these changes become more prominent over time.

Key words: Diabetes Mellitus, Ultrasonography, Pancreas, Insulin

\section{INTRODUCTION}

The pancreas is a non-encapsulated, retroperitoneal organ that is present in the anterior para-renal space among the duodenal loop and splenic hilum over a length of 12.5-15 $\mathrm{cm}$. There are numerous types of morphological variations in the pancreas which have been labeled in patients with diabetes mellitus (DM). Islet cell pancreatic changes in diabetes mellitus such as hyalinization, fibrosis, hydropic degeneration, and hyperplasia are well shown. Additionally, cellular composition of the pancreas in Type 2 diabetes have shown a decrease in beta cell mass. ${ }^{1}$

$\mathrm{DM}$ is a chronic metabolic disorder of various etiology, categorized by hyperglycemia with changes in carbohydrate, fat, and protein metabolism, resulting from a relative or an absolute lack of insulin. There are two types of diabetes; the Type 1 DM (IDDM) and the Type 2 DM (non-IDDM). In Type $1 \mathrm{DM}$, there is autoimmune attack and damage of the pancreas insulin-producing cells; whereas in Type 2 DM, the pancreas loses its capacity to appropriately produce and release insulin and the body also becomes resistant to insulin, thereby producing the blood sugar levels to rise. ${ }^{2}$

The worldwide incidence of DM has risen intensely over the past two decades. ${ }^{3}$ There are two types of DM: type
I which is an autoimmune disorder with infiltration of inflammatory cells in Islets of Langerhans and distraction of pancreatic beta cells 3 and type II which is characterized with disorder in insulin secretion, peripheral resistance to insulin and overproduction of glucose by liver. ${ }^{4,5}$ The ultrasound is a non- invasive imaging tool that sends the sound and receives the echoes to visualize in great detail organs. The placement of the pancreas in the abdomen suits best to view by ultrasound examination. Though, the complex anatomy of the organ and surrounding tissues make assessment a difficult task, and the ultrasound echo of the normal pancreas varies widely from patient to patient. ${ }^{6}$ Hence this study evaluated the pancreatic size of diabetic patients using ultrasonography and also accessed whether there is an association among the size of the pancreas and the duration of diabetes.

\section{MATERIAL AND METHODS}

This observational study was conducted from the cases admitted to Malla Reddy Institute of Medical Sciences Hospital, Hyderabad during the period from June 2015 to October 2016.30 cases of each type of diabetes were selected in this study. Ultrasound investigations were performed to measure pancreas head and diameter by using ultrasound 


\begin{tabular}{|l|l|c|}
\hline \multirow{2}{*}{ Insulin dependent diabetic patients } & \multicolumn{2}{|c|}{ Parameters (means \pm SD) } \\
\cline { 2 - 3 } & Pancreatic head & $17.5 \pm 2.5 \mathrm{MM}$ \\
\cline { 2 - 3 } & Pancreatic tail & $7.4 \pm 1.6 \mathrm{MM}$ \\
\hline Non insulin dependent patients & Pancreatic head & $21.1 \pm 3.5 \mathrm{MM}$ \\
\cline { 2 - 3 } & Pancreatic tail & $9.0 \pm 2.6 \mathrm{MM}$ \\
\hline \multicolumn{2}{|c|}{ Table-1: Showing the parameters in insulin and non -insulin diabetic patients } \\
\hline
\end{tabular}

machine Toshiba- Xario100 transabdominal convex transducer with frequency of $3.5 \mathrm{MHz}$. Inclusion criteria the study included all patients above 20 years old, who they had diabetes milletus (type -1 and 2). Exclusion criteria - Patients of pediatric age group and had any pancreatic abnormalities (cirrhosis, thalassemia, pancreatitis, pancreatic tumors or cystic fibrosis). Cases selection was performed based on history, clinical examination and ultrasound examination. The echogenicity of pancreas was related to that of liver (as a reference). Study was conducted under the following parameters: History taking, Clinical examination and Ultrasound examination.

\section{STATISTICAL ANALYSIS}

Data collection and analysis were done by using Statistical Package for Social Sciences (SPSS) software (version 16, SPSS, Inc, Chicago, IL, USA) for both study groups. Oneway ANOVA test and Student's T-test were performed to estimate the size of head and body of pancreas and pancreas echogenicity in various groups. Pearson correlation was performed to assess the relationship between the size of the pancreas and the duration of diabetes.

\section{RESULTS}

There was a significant difference $(\mathrm{P}=0.001)$ observed when comparing mean pancreatic body size of diabetic patients group (type I and II) to that of control group. Mean pancreatic head and body size was $17.5 \pm 2.5 \mathrm{~mm}$ and $7.4 \pm$ $1.6 \mathrm{~mm}$ in insulin dependent diabetic patients and $21.1 \pm$ $3.5 \mathrm{~mm}$ and $9.0 \pm 2.1 \mathrm{~mm}$ in noninsulin dependent diabetic patients and $26.2 \pm 4 \mathrm{~mm}$ and $14.1 \pm 2.6 \mathrm{~mm}$ in the control group (table 1). A statistically significance observed among the three groups $(\mathrm{P}<0.001)$. In all three groups, the control group observed the highest value, whereas the type I DM patients showed the smallest value of pancreas head and body size. No significant difference in pancreas echogenicity was noted among the groups. There was a negative correlation observed between the size of pancreas head and body with the duration of disease $(\mathrm{P}<0.001)$.

\section{DISCUSSION}

About 171 million people had diabetes mellitus globally by the year 2000, and the total number is established to rise to 366 million by 2030 . The incidence of diabetes is $9.8 \%$, with a male: female ratio of $1.4: 1$ and this upsurge in the incidence of diabetes mellitus in developing countries due to development of urbanization and lifestyle deviations, most prominently being the western style diet. ${ }^{7}$

The quick-tempered increase in number of people identified with diabetes mellitus stances a overwhelming negative economic impact and human cost creating this disease a new health risk in the 21st century. Considering the etiology of the disease, ensuring quick diagnosis and outcome a way to prevent it is a crucial challenge for health care providers. $^{8}$

Diabetes mellitus affects both the lifespan and quality of life of the individual. The disease causes serious restraints on the patient's activities, especially when there is poor management of the disorder. This creates the diabetic person to be partially or totally dependent. ${ }^{9,10}$

Abdominal ultrasound has a great benefit over plain radiography in that it does not prompt tissues to the danger of ionizing radiation. Ultrasound is commonly far superior than plain radiography in uniqueness for understanding variation of soft tissue structure.

Result of this study presented that the antero-posterior diameter of head and body of pancreas had significantly reduced in the diabetic group when compared with healthy controls. This was in concurrence of earlier studies. ${ }^{11,12}$ An earlier study on autopsy samples by Foulis et al established that in type I diabetic patients, irrespective of whether or not greater than 23 percent of island cells are affected by insulitis (inflammatory cell infiltration), significant reductions happen in the size and weight of pancreas ${ }^{13}$; additional studies have documented lack of the trophic effect of insulin as the reason. ${ }^{14}$

Our results noted that the mean diameters of head and body of pancreas in types I and II diabetes mellitus patients were significantly changed when compared with healthy controls. Type I diabetic patient had the smallest mean values whereas healthy controls had the largest values. Previous studies showed that diameters of pancreas were greatly reduced in type I diabetes mellitus compared with type II DM and these were significantly less than in the normal group. ${ }^{13,15}$ Conferring to the results of this study and other studies, it is concluded that ultrasonography could be a suitable technique for distinguishing two types of diabetes mellitus; for functional uses, though, more relative evaluation of the two groups is essential. Unlike type II diabetic patients, pancreatic head diameter in type I diabetic patients was less than $15 \mathrm{~mm}$. From this study, there was a direct correlation between head and body of pancreas; also an inverse correlation was observed between these two diameters and period of disease. A study performed by Altobelli et al (1988) demonstrated that longer duration of disease is achieved by greater decrease in pancreatic $\operatorname{size}^{16}$, but the study of Foulis in 1984 didn't validate this result ${ }^{12}$; echogenicity of the pancreas was considerably different. However Walls et al. ${ }^{17}$ observed an increased echogenicity of the gland in type II diabetes compared with type I diabetes patients. ${ }^{18}$ For further investigation, studies with greater sample size is necessary. In view of the fluctuating results of earlier studies, this work attempted to estimate ultrasonographic deviations of pancreas in diabetic patients. 


\section{CONCLUSION}

A decrease in the size of pancreas was noted predominantly in type 1 diabetes when compared to type II diabetes and these changes develop more prominent over time. It is recommended that pancreas size measurements should be included as screening parameters for uncertain cases of DM while fasting blood sugar test must be done for related cases of decreased pancreas dimensions observed on sonography.

\section{REFERENCE}

1. Roger S, Tom W. Clinical Sonography, a Practical Guide. 4th ed. New York: Lippincott Williams and Wilkins; 2007. p. 54-62.

2. Ravi R, Mani R, Sanjeev M, Goyal RK, Verma GL. Pancreatic imaging by ultrasonography in type 1 diabetes mellitus. Int J Diabetes Metab 2001;9(1):7580.

3. Pickup J, Williams G. Textbook of diabetes. 2nd ed. London: Blackwell Science; 1998.

4. Bagher Larejani, Farzaneh Zahedi. Epidemiology of diabetes mellitus in Iran. Iranian Journal of Diabetes and Metabolism 2001;1(8):1-8.

5. Powers AC. Diabetes Mellitus. In: Kasper D, Braunwald E, Fauci A, Hanser S, Longo D, Jameson J, editors. Harrison's principles of internal medicine. New York: McGraw-Hill; 2005. p. 2152-2180.

6. Chessler SD, Lernmark A. Type I (insulin dependent) diabetes mellitus. In: John $\mathrm{KD}$, editor. Clinical diabetes mellitus: a problem oriented approach. New York: Thieme; 2006. p. 37-57.

7. Omorogiuwa A, Oaikhena G, Okoye P, Akubueze D, Owobu E, Enahoro I, et al. Diabetes mellitus: Prevalence among University Staff in Southern Nigeria and attitude towards routine glycemic/glucosemic checkup. Int J Biomed Health Sci 2010;6(2):1-8.

8. Ikekpeazu EJ, Neboh EE, Maduka IC, Nwagbara IJ, Nwobodo MW. Type-2 diabetes mellitus and malaria parasitaemia: Effect on liver function test. Asian J Med Sci 2010;2(4):214-7.

9. Dong C. Prevalence, predisposition and prevention of type II diabetes. Nutr Metab 2005;2(6):29-39.

10. Issa B, Baiyewu O. Quality of life of patients with diabetes mellitus in a Nigerian teaching hospital. Hong Kong J Psychiatry 2006;16(2):27-33

11. Daniel Longnecker, MD Anatomy and Histology of the Pancreas.[DOI: 10.3998/panc.2014].

12. Foulis AK, Frier BM. Pancreatic endocrine-exocrine function in diabetes: an old alliance disturbed. Diabet Med 1984; 1(4):263-266.

13. Goda K, Sasaki E, Nagata K, Fukai M, Ohsawa N, Hahafusa T. Pancreatic volume in type 1 and type 2 diabetes mellitus. Acta Diabetol 2001; 38(3):145-149.

14. Foulis AK, Stewart JA. The pancreas in recent-onset type 1 (insulin-dependent) diabetes mellitus: insulin content of islets, insulitis and associated changes in the exocrine acinar tissue. Diabetologia 1984; 26(6):456461.

15. Alzaid A, Aideyan O, Nawaz S. The size of the pancreas in diabetes mellitus. Diabet Med 1993; 10(8):759-763.

16. Altobelli E, Blasetti A, Verrotti A, Di G, V, Bonomo L,
Chiarelli F. Size of pancreas in children and adolescents with type I (insulin-dependent) diabetes. J Clin Ultrasound 1998; 26(8):391-395.

17. Walls WJ, Gonzalez G, Martin NL, Templeton AW. B-scan ultrasound evaluation of the pancreas. Advantages and accuracy compared to other diagnostic techniques. Radiology 1975; 114(1):127-134

18. Goda K, Sasaki E, Nagata K, Fukai M, Ohsawa N, Hahafusa T. Pancreatic volume in type 1 and type 2 diabetes mellitus. Acta Diabetol 2001; 38(3):145-149.

\section{Source of Support: Nil; Conflict of Interest: None}

Submitted: 05-08-2018; Accepted: 07-09-2018; Published online: 02-01-2019 